\title{
Research Paper: Comparing the Effect of TRX Ex- ercise and Hoping on Balance in Male University Student Athletes
}

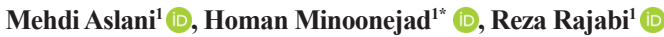

1. Department of Sport Pathology and Corrective Exercises, Faculty of Physical Education and Sport Sciences, University of Tehran, Tehran, Iran.

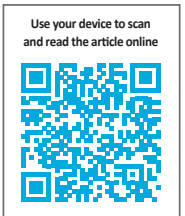

Crtation Aslani M, Minoonejad H, Rajabi R. Comparing the Effect of TRX Exercise and Hoping on Balance in Male University Student Athletes. Physical Treatments. 2018; 7(4):241-250. http://dx.doi.org/10.32598/ptj.7.4.241

doi : : http://dx.doi.org/10.32598/ptj.7.4.241

Funding: See Page 246

\section{(c) (i) (3)}

Article info:

Received: 26 Jun 2017

Accepted: 12 Nov 2017

Available Online: 01 Jan 2018

Keywords:

TRX exercises, Total body resistance exercises, Hopping exercises, Balance

\begin{abstract}
A B S T R A C T
Purpose: This study aimed to compare the effect of 4 weeks of suspension exercises with TRX and hopping on the static and dynamic balance of male college athletes.

Methods: This was a quasi-experimental study. In total, 36 male volleyball, basketball, soccer and handball players of the University of Tehran with an age range between 20 and 28 years were selected purposefully and then randomly assigned into 3 groups of control $(n=12)$, TRX suspension exercise $(n=12)$, and hopping exercise $(n=12)$. The exercise groups performed hopping and TRX exercise 3 sessions a week for 4 weeks (12 sessions). Static and dynamic balance of the participants were measured before and after 4 weeks of suspension exercises with TRX and hopping using Biodex balance system. For data analysis paired $t$ test, ANCOVA and Bonferroni test were performed in SPSS. $\mathrm{P} \leq 0.05$ was considered as the significant level.
\end{abstract}

Results: The scores of the general indicator of the static and dynamic balance test in the 2 exercise groups showed significant improvements, compared to the control group ( $\mathrm{P} \leq 0.05)$. However, there was no significant difference between the effect of hopping and TRX exercise on the static and dynamic balance of the athletes $(\mathrm{P}>0.05)$.

Conclusion: Four weeks of hopping and TRX exercise significantly improves the static and dynamic balance of college athletes; Athletes and coaches can use both of these 2 sets of exercises for improving the static and dynamic balance and for prevention of injury.

\section{* Corresponding Author:}

Homan Minoonejad, PhD

Address: Department of Sport Pathology and Corrective Exercises, Faculty of Physical Education and Sport Sciences, University of Tehran, Tehran, Iran. Phone:+98 (936) 5086156

E-mail:h.minoonejad@ut.ac.ir 


\section{Highlights}

- Both hopping and TRX exercises can improve the balance in athletes and can be used to prevent their injury.

\section{Plain Language Summary}

Balance deficits are one of the factors contributing to the injury of athletes. Therefore, it is necessary to find the best and most cost-effective way to improve the balance in athletes. In this study, 36 male athletes of volleyball, basketball, soccer and handball players of the University of Tehran were selected. The exercise groups carried out hopping and TRX exercises 3 sessions per week for 4 weeks (12 sessions). According to the results, both hopping and TRX exercises had a significant effect on the static and dynamic balance and performance of the athletes, and both exercises can be used to prevent injury and improve static and dynamic stability and performance of players. Also, given that less time and equipment is needed to use hopping exercise compared to the TRX exercise, it can be employed with less time and cost in the trainings programs of the sports mentioned above. Beginner and professional athletes can safely increase the intensity of exercise without increasing external resistance by using TRX exercise which can reduce the risk of injury. In addition, athletes can use the TRX exercises as a diversity training, which is one of the principles of education, along with their other exercises to prevent the body from adapting to the exercise stimuli. Furthermore, due to the attractiveness and novelty of the TRX exercise compared to hopping exercise, athletes and coaches are more likely to use TRX exercise rather than hopping.

\section{Introduction}

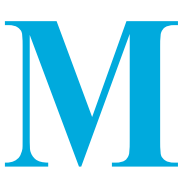

any physical activities are accompanied with injury. For many professional and non-professional athletes, the occurrence of these injuries are already accepted to participate in sports and championship activities [1]. Each

injury not only is accompanied with pain and incapability, but also holds the athlete back from sport fields and can impose direct and indirect costs on the athlete and the sport club $[2,3]$.

Studies indicate that most of sport associated injuries relate to the lower limbs [4]. Athletes who participate in volleyball, basketball, handball and soccer should suddenly change their movement directions during a sport game, or rapidly reduce their speed, or perform jumping, leaping, landing and sudden stops, that make them more susceptible to lower limb injury compared to other sports [5-8]. Therefore, prevention of injury to the joints of lower limbs in these sports seems necessary. One of the most important risk factors for knee and ankle injury is impaired postural control and balance. Postural control and balance are the most important abilities of athletes.

Accordingly, it is a determining indicator in examining the functional ability of athletes [9]. For this reason, prescribing exercises to improve postural control and the balance of lower limb joints are necessary to prevent injury and better function of the athlete. Conventional exercise programs to prevent and rehabilitate injuries include strength exercises, balance exercises, core stability, and plyometric exercises [10-13]. Because sports like basketball, volleyball, soccer and handball require jumping and landing, hopping exercises can be suitable for these athletes. Hopping exercises are considered as plyometric and among basic and fundamental motor skills that are low-cost and trainable. In addition, they can be employed in sport programs as part of the workout schedule [10].

The effect of hopping exercises on improvement of the static and dynamic balance of athletes and non-athletes have been reported in domestic and foreign studies. For example, Karimizadeh et al. (2012) assessed the effect of hopping exercises on the dynamic balance of athletes with functional instability in their ankles. They reported that hopping exercises significantly increase the distance of the reach of the participants in each of the 8 directions of the Star Excursion Balance Test [10]. However, researchers believe that in the event of an injury, the entire body should be considered as a system that the defect in each part of it can affect the function of other parts [14].

Camerford and Mottram indicated that the stability of core parts of the body is imperative for safe and efficient movement of the limbs and especially the lower limbs. In fact, the trunk and core parts of the body should be sufficiently stable to have efficient lower limb functional movements with minimal injury [15]. In addition, the effect of core stability exercises on improving the bal- 
ance of athletes has been reported by researchers [16, 17]. Suspension exercises with TRX is a new functional exercise method by which hundreds of different types of exercises can be performed. It uses the force of gravity or body weight with 2 rope-like levers for different purposes. It has recently drawn the attention of people attending sports and exercise. Studies show that the unique feature of TRX exercises, compared to other exercise methods, is to activate the body's core stabilizing muscles by changing the body position, in the upper and lower limb movements [18].

Other researchers also referred to the high electrical activity of the core stabilizing muscles when performing movements like plank exercises on unstable surfaces such as TRX, compared to stable surfaces like the ground $[19,20]$. Moreover, in some studies, TRX has been considered a destabilizing device that besides core stability exercises, it can be used to design all types of balance, neural and muscular exercises [19-22]. Literature review revealed that core stabilizing muscles have a significant effect on improving the athletes balance, and TRX exercises largely emphasizes on improving the function of core stabilizing muscles.

The effectiveness of hopping exercises has already been reported for improving athlete balance; however, this effectiveness has not been compared with other exercise methods. Therefore, the present study aimed to compare the effects of hopping and TRX exercises on the static and dynamic balance of male college athletes.

\section{Materials and Methods}

This was a quasi-experimental study with pretest, posttest design, and two experimental (TRX and hopping exercises) and one control groups. The statistical population of this study consisted of college athletes engaged in volleyball, basketball, soccer and handball, among whom 36 athletes were selected purposefully according to the research inclusion and exclusion criteria. Then, they were randomly divided into a control group and two experimental groups (hopping and TRX exercises). The inclusion criteria consisted of athletes aged 20 to 28 years, practiced at least 3 years in volleyball, basketball, soccer, or handball, could perform 5 squats in 5 seconds with $60 \%$ of the body weight (as a precondition for entering to hopping exercises) [23], lacked any pathologic symptoms and history of fracture, operation, or joint illnesses in the lower limbs or spine within the past 5 years $[24,25]$.

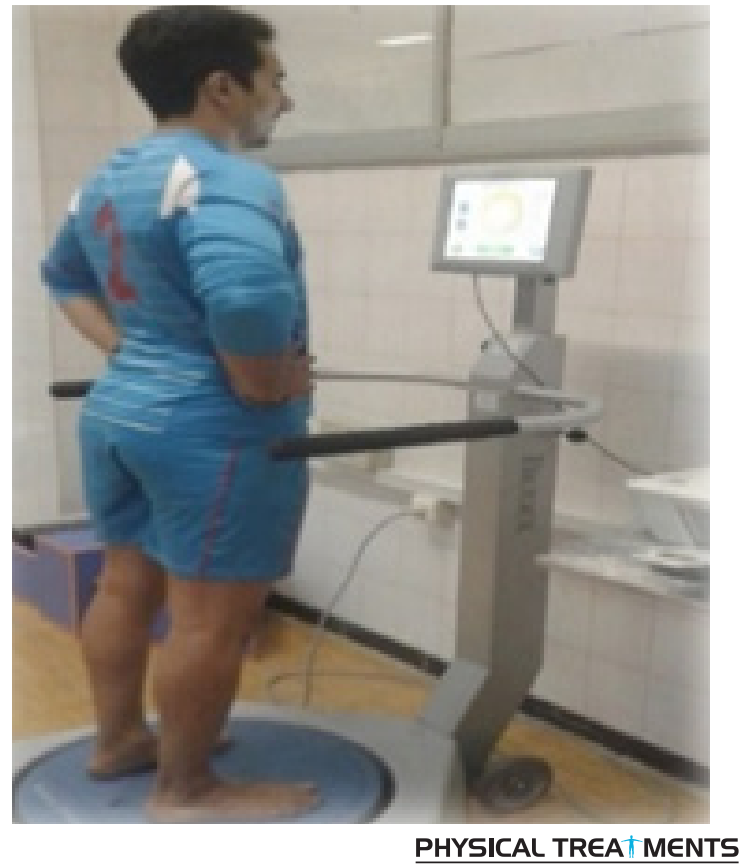

Figure 1. Biodex Balance System

The exclusion criteria were pain in any part of the body during the performance of test in a way that the athlete would not be able to cooperate [25] and more than 2 absences from the exercise sessions [26]. After the research samples were selected based on inclusion and exclusion criteria, they were randomly divided into three groups: 1. Hopping exercises $(n=12)$ with an Mean \pm SD age of $25.22 \pm 2.32$ years, height $176.10 \pm 0.13 \mathrm{~cm}$, body weight $71.85 \pm 5.15 \mathrm{~kg}$, and body mass index $21.98 \pm 1.19 \mathrm{~kg} / \mathrm{m}^{2}$; 2. TRX exercise group $(\mathrm{n}=12)$ with the Mean \pm SD age of $26.79 \pm 1.84$ years, height $177 \pm 6.38 \mathrm{~cm}$, body weight $72.70 \pm 6.31 \mathrm{~kg}$, and body mass index $22.42 \pm 1.19 \mathrm{~kg} / \mathrm{m}^{2}$; and 3. The control group $(\mathrm{n}=12)$ with an Mean \pm SD age of $24.85 \pm 3.26$ year, height $174.72 \pm 5.95 \mathrm{~cm}$, body weight $67.18 \pm 11.42 \mathrm{~kg}$ and body mass index $22.92 \pm 2.34 \mathrm{~kg} / \mathrm{m}^{2}$.

For pretest measurements, the research samples were invited to the sports hall according to the specified timetable. Subsequently, the initial information form was completed by each athlete and anthropometric measurements (weight, height, waist and hip circumference) of each person were obtained. Then, measurements related to the static and dynamic balance of the participants were collected. For measuring the static and dynamic balance, the Biodex Balance System was used. This system consists of a moving circle plate to station the participant (balance meter plate), a monitor, and an electronic processor (Figure 1)

In this research, the dynamic balance of athletes was assessed at instability level 4 (great instability) and the 
static balance was assessed at a static level and only by the overall indicator. The lower values on the balance system, denotes better athlete balance and vice versa. After completing pretest measurements, the experimental group performed TRX and hopping exercises for 4 weeks, 3 sessions per week, under the supervision of the researcher (Appendix 1, 2, 3, and 4).

The control group was asked not to do any special sports activities during the study period and only perform their usual daily activities. A training session was held to familiarize the experimental groups' samples with the method of performing TRX and hopping exercises, prior to the onset of exercises. TRX and hopping exercise session comprised an initial 10-min warm-up followed by 30 to $40 \mathrm{~min}$ of selected TRX and hopping exercises under the supervision of the researcher. All of the movements that were performed in TRX exercises were based on related references and articles published in the field of suspension TRX exercises [27, 28].

The researcher has also designed the protocol for TRX suspension exercises, based on 1-year coaching experience in this field. TRX exercises included exercises for the lower limbs as well as the plyometric and balance basis, so that it could be compared with hopping exercises, and also the volume and intensity of both exercises were matched by the researcher in accordance with the principles of FITT (frequency, intensity, time spent and type of exercise) and then confirmed by a specialist physician. Next, the descriptive statistical tests of mean and standard deviation were used to describe the data, and the paired t test was used to compare the intra-group results.

The Analysis of Covariance (ANCOVA) was used to compare inter-group variables. All statistical analyses were performed at the significance level of 0.05 using SPSS. To determine the normality of data, the ShapiroWilk statistical test was used which confirmed the normal distribution of data.

\section{Results}

A significance level was considered in all tests $(\mathrm{P} \leq 0.05)$ (Table 1). The results of paired t test showed a significant difference between the pretest and posttest in the static and dynamic balance of athletes in the exercise groups of TRX and hopping, in a way that the balance fluctuations in the posttest in these two groups reduced after 4 weeks of exercise, compared to the pretest $(\mathrm{P} \leq 0.05)$. This result indicates a significant improvement in the static and dynamic balance in both groups; however, no significant difference was seen in those variables, among the control group members $(\mathrm{P}>0.05)$.

ANCOVA was applied to compare the difference among 3 groups in the static and dynamic balance scores. The obtained results are reported in Table 2 which indicate a significant difference among 3 study groups in terms of the dynamic and static balance of the athletes in the posttest $(\mathrm{P} \leq 0.05)$, after controlling the effect of pretest results (covariate). Therefore, the Bonferroni post-hoc test was used to examine the inter-group difference (Table 2).

The results of Bonferroni post-hoc test indicate no significant differences between the TRX exercise and hopping groups $(\mathrm{P}=1.00)$ in the dynamic balance test. However, a significant difference was found between the control group and the hopping group $(\mathrm{P}=0.001)$ as well as the control group and the TRX group $(\mathrm{P}=0.001)$.In addition, in the static balance test, there was no significant difference between the TRX and hopping groups

Table 1. Results of the paired $t$ test and ANCOVA to investigate the intra-group and inter-group differences

\begin{tabular}{|c|c|c|c|c|c|c|c|c|c|}
\hline \multicolumn{2}{|c|}{ Variables } & $\begin{array}{l}\text { Control } \\
\text { Group }\end{array}$ & $t(p)$ & TRX & $t(p)$ & Hopping & $t(p)$ & $F(p)$ & $\begin{array}{c}\text { Partial } \\
\text { Eta-Squared }\end{array}$ \\
\hline \multirow{3}{*}{$\begin{array}{l}\text { Static balance } \\
\text { (OA) }\end{array}$} & Pretest & $1.00 \pm 0.24$ & & $0.98 \pm 0.28$ & & $0.96 \pm 0.27$ & \multirow{3}{*}{$2.61(0.024)^{*}$} & \multirow{3}{*}{$23.04(0.001)^{*}$} & \multirow{3}{*}{0.58} \\
\hline & $\begin{array}{l}\text { Post- } \\
\text { test }\end{array}$ & $1.07 \pm 0.16$ & $-0.65(0.52)$ & $0.71 \pm 0.18$ & $3.99(0.002)^{*}$ & $0.77 \pm 0.07$ & & & \\
\hline & $95 \% \mathrm{Cl}$ & $1.09,0.95$ & & $0.78,0.64$ & & $0.85,0.70$ & & & \\
\hline \multirow{4}{*}{$\begin{array}{c}\text { Dynamic } \\
\text { balance }(\mathrm{OA})\end{array}$} & Pretest & $2.70 \pm 0.21$ & \multirow{4}{*}{$-1.00(0.33)$} & $2.71 \pm 0.29$ & \multirow{4}{*}{$9.47(0.001)^{*}$} & $2.88 \pm 0.37$ & \multirow{4}{*}{$6.53(0.001)^{*}$} & \multirow{4}{*}{$25.73(0.001)^{*}$} & \multirow{4}{*}{0.6} \\
\hline & & & & & & & & & \\
\hline & $\begin{array}{l}\text { Post- } \\
\text { test }\end{array}$ & $2.73 \pm 0.23$ & & $2.33 \pm 0.37$ & & $2.46 \pm 0.36$ & & & \\
\hline & $95 \% \mathrm{Cl}$ & $2.89,2.69$ & & $2.48 \pm 2.28$ & & $2.45,2.25$ & & & \\
\hline
\end{tabular}

* Sig.: $\mathrm{P}<0.05$ 


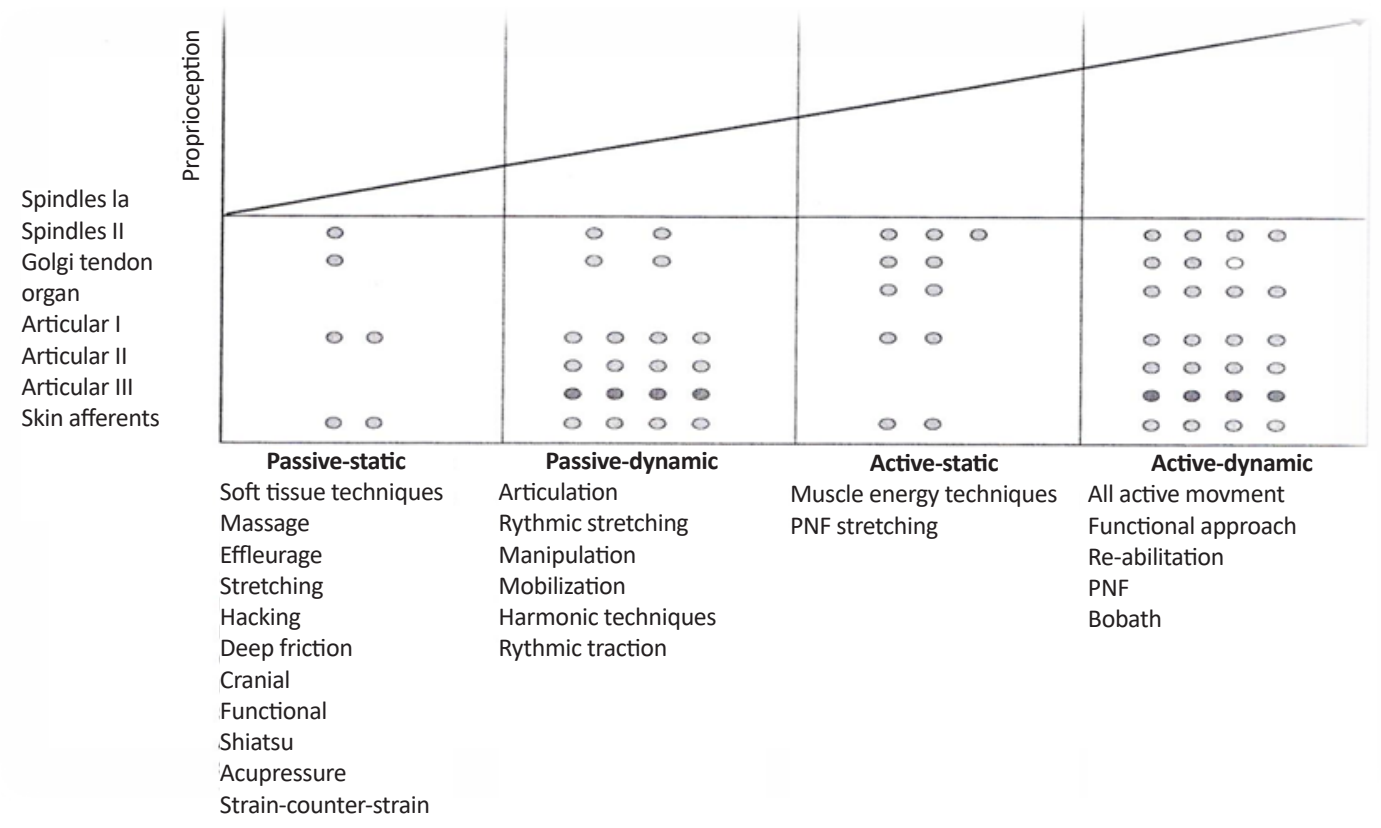

Figure 2. Contribution of exercises in improving the proprioceptive sense

PHYSICAL TREA $\mid$ MENTS

$(\mathrm{P}=0.56)$; however, the differences between the control and hopping groups $(\mathrm{P}=0.001)$ as well as the control group and TRX group $(\mathrm{P}=0.001)$ were significant.

\section{Discussion}

The present study aimed to compare the effect of 4 weeks of suspension exercise with TRX and hoping exercise on some risk factors for the lower limbs injury in male college athletes. The static, dynamic balance test, and stability limits in the two exercise groups showed significant improvement, compared to the control group $(\mathrm{P}<0.05)$. However, there was no significant differences between the effect of hopping and TRX exercises on the static and dynamic balance of athletes $(\mathrm{P}>0.05)$.
Hobscher et al. in a review study of balance and neuromuscular exercises concluded that the balance and neuromuscular exercises improve the neuromuscular connection and by reducing the delay in proprioceptive sensory function, the acute injuries in ankle and knee areas reduce significantly. Such exercises could be performed to improve the balance of athletes due to better neuromuscular coordination and increased coordination of vision, vestibular, and proprioceptive systems. Therefore, the exercises designed in this study, may be able to improve the balance by improving the efficiency of sensory receptors and neuromuscular facility, while improving the proprioceptive sense of the joints [29]. Figure 2 by Joseffine Kee et al. shows the contribution of various exercises in improving the proprioceptive sense.

Table 2. Results of Bonferroni test to investigate inter-group differences in each group

\begin{tabular}{cccc}
\hline Variable & Groups & Adjusted Median & Bonferroni Test Results \\
\hline & Control & $1.02 \pm 0.03$ & $0.56^{\mathrm{a}}$ \\
Static balance (OA) & TRX & $0.71 \pm 0.03$ & $0.001^{\mathrm{b}}$ \\
& Hopping & $0.78 \pm 0.03$ & $0.001^{\mathrm{c}}$ \\
& Control & $2.79 \pm 0.04$ & $1.00^{\mathrm{k}}$ \\
Dynamic balance (OA) & TRX & $2.37 \pm 0.04$ & $0.001^{\mathrm{b}}$ \\
& Hopping & $2.35 \pm 0.05$ & $0.001^{\mathrm{c}}$ \\
\hline
\end{tabular}

a: Comparison between TRX and hopping; b: Comparison between the control group and TRX group; c: Comparison between control and hopping; $\mathrm{k}$ : Comparison between TRX and hopping 
Only in dynamic conditions, all 4 muscular receptors are activated and the proprioceptive sense is strengthened.

Considering the previous studies, exercises with traction-contraction mechanism can improve and change the start of muscular activity and may also indirectly affect the feed-forward. This mechanism is considered in the treatment and prevention of lower limb injuries [30]. According to the study findings, these exercises improve the static and dynamic balance and the limits of athlete stability. Designing an exercise program to strengthen balance and ameliorate posture fluctuation is an appropriate tool for preventing injury and a safer and quicker method for the athletes to recover from injuries.

The athletes who participated in this study were selected from the field of basketball, volleyball, football and handball. In these sports, zigzag movements and cutting, jumping, and landing maneuvers are risk factors for many lower limb non-contact injuries. Thus, the hopping and TRX exercise programs that require both legs and single-leg jumping and landing, as well as cutting maneuvers and zigzag movements without the loss of balance with high agility and speed in the frontal and sagittal directions, can improve the balance function in these athletes [31].

One of the most important characteristics of suspension exercises is the proper activation of the core stabilizing muscles in all movements performed with TRX [32]. Research results have supported a direct connection between the core stabilizing muscles and the ability to maintain balance [33]. In fact, TRX exercises not only strengthen the body main motional muscles, but also strengthen the core stabilizing muscles by performing a functional activity [34]. It can be concluded that both exercises can have a desirable effect on the static and dynamic balance of athletes.

In conclusion, employing these exercises with our study designed protocol may be a safer and more suitable way for beginner athletes. They can learn the correct technique of performing the movements with fewer mistakes in the exercise. They can also diversify their exercises to prevent their bodies get used to boring exercises which is one of the principles in exercise design. These types of exercises can also be used alongside other exercise protocols.

The effect of hopping exercise in improving the static and dynamic balance of athletes and non-athletes have been reported in domestic and foreign studies; however, we are still witnessing injuries of the lower limbs in these athletes. On the other hand, the core stabilizing muscles have a significant effect on improvement of athletes' balance. In this regard, TRX exercises emphasizes on improving the function of core stabilizing muscles. The effectiveness of hopping exercise on improvement of athletes balance has been already reported; however, this effectiveness has not been compared with other exercise methods.

Considering the results of this study, both hopping and TRX exercises have significant impacts on the static and dynamic balance of athletes, and both of these exercises can be used by athletes engaged in basketball, volleyball, football, and handball. However, in the discourse on prevention of sports injuries, final decision in rejecting or accepting TRX exercises cannot be made due to limited studies in this regard, and further studies should be conducted.

\section{Ethical Considerations}

\section{Compliance with ethical guidelines}

All ethical principles were considered in this article. The participants were informed about the purpose of the research and its implementation stages; They were also assured about the confidentiality of their information; Moreover, They were allowed to leave the study whenever they wish, and if desired, the results of the research would be available to them. The consent form for voluntary and informed participation in the research was signed by participants.

\section{Funding}

This study is part of the curriculum of studies of sports pathology and corrective movements at the University of Tehran. This research did not receive any specific grant from funding agencies in the public, commercial, or notfor-profit sectors.

\section{Conflict of interest}

The authors certify that they have no affiliation with or involvement in any organization or entity with any financial interest, or non-financial interest in the subject matter or materials dismissed in this manuscript.

\section{Acknowledgments}

Authors of this study hereby express their gratitude to all those who assisted in conducting this study. 


\section{References}

[1] Eisenhart AW, Gaeta TJ, Yens DP. Osteopathic manipulative treatment in the emergency department for patients with acute ankle injuries. The Journal of the American Osteopathic Association. 2003; 103(9):417-21. [PMID]

[2] Panics G, Tallay A, Pavlik A, Berkes I. The effect of proprioception training on knee joint position sense in female team handball players. British Journal of Sports Medicine. 2008; 42(6):472-6. [DOI:10.1136/bjsm.2008.046516] [PMID]

[3] Mcguine TA, Greene JJ, Best T, Leverson G. Balance as a predictor of ankle injuries in high school basketball players. Clinical Journal of Sport Medicine. 2000; 10(4):239-44. [DOI:10.1097/00042752-200010000-00003] [PMID]

[4] Gribble PA, Robinson RH. Alterations in knee kinematics and dynamic stability associated with chronic ankle instability. Journal of Athletic Training. 2009; 44(4):350-5. [DOI:10.4085/1062-6050-44.4.350] [PMID] [PMCID]

[5] Foss KD, Myer GD, Hewett TE. Epidemiology of basketball, soccer, and volleyball injuries in middle-school female athletes. The Physician and Sports Medicine. 2014; 42(2):146-53. [DOI:10.3810/psm.2014.05.2066] [PMID] [PMCID]

[6] Laver L, Myklebust G. Handball injuries: Epidemiology and injury characterization. In: Doral MN, Karlsson J, editors. Sports Injuries: Prevention, Diagnosis, Treatment and Rehabilitation. Berlin: Springer; 2015.

[7] Bere T, Alonso JM, Wangensteen A, Bakken A, Eirale C, Dijkstra HP, et al. Injury and illness surveillance during the 24th Men's Handball World Championship 2015 in Qatar. British Journal of Sports Medicine. 2015; 49(17):1151-6. [DOI:10.1136/bjsports-2015-094972] [PMID]

[8] Falese L, Della Valle P, Federico B. Epidemiology of football (soccer) injuries in the 2012/2013 and 2013/2014 seasons of the Italian Serie A. Research in Sports Medicine. 2016; 24(4):426-32. [DOI:10.1080/15438627.2016.1239105] [PMID]

[9] Pashabadi A, Farokhi A, Jamshidi AA, Shahbazi M. [Effect of attentional focus on postural sways and muscular activity in athletes (Persian)]. Journal of Modern Rehabilitation. 2014; 8(1):28-34

[10] Karimizadeh Ardakani M, Alizadeh MH, Ebrahimi Takamjani E. [The effect of six weeks Hopping exercise on joint position sence of athlete with functional ankle instability (Persian)]. Isfehan University of Medical Sciences. 2012; 9(3):139-51.

[11] Samadi H, Rajabi R, Alizadeh MH, Jamshidi A. [Effect of six week neuromusccular training on dynamic postural control and lower extremity function in male athletes with functional ankle instability (Persian)]. Studies of Sports Medici. 2014; 5(14):73-90.

[12] Yun YD, Shin HJ, Kim SJ, Lim SW, Choi SJ, Seo DK, et al The effects of resistance exercise and balance exercise on proprioception and WOMAC index of patients with degenerative knee osteoarthritis. Journal of International Academy of Physical Therapy Research. 2010; 1(2):169-75.

[13] Sukerkar P. EEG source localization of visual and proprioceptive error processing during visually-guided target Tracking with the wrist. Milwaukee, Wisconsin: Marquette University; 2010.
[14] Page P, Frank CC, Lardner R. Assessment and treatment of muscle imbalance: The Janda approach. Champaign, Illinois: Human kinetics; 2010.

[15] Comerford MJ, Mottram SL. Functional stability re-training: principles and strategies for managing mechanical dysfunction. Manual Therapy. 2001; 6(1):3-14. [DOI:10.1054/ math.2000.0389] [PMID]

[16] Watson T, Graning J, McPherson S, Carter E, Edwards J, Melcher I, et al. Dance, balance and core muscle performance measures are improved following a 9-week core stabilization training program among competitive collegiate dancers. International Journal of Sports Physical Therapy. 2017; 12(1):25-41. [PMCID]

[17] Hassan IH. The effect of core stability training on dynamic balance and smash stroke performance in badminton players. International Journal of Sports Science and Physical Education. 2017; 2(3):44-52.

[18] Janot J, Heltne T, Welles C, Riedl J, Anderson H, Howard A, et al. Effects of TRX versus traditional resistance training programs on measures of muscular performance in adults. Journal of Fitness Research. 2013; 2(2):23-38.

[19] Byrne JM, Bishop NS, Caines AM, Crane KA, Feaver AM, Pearcey GE. Effect of using a suspension training system on muscle activation during the performance of a front plank exercise. The Journal of Strength \& Conditioning Research. 2014 28(11):3049-55. [DOI:10.1519/JSC.0000000000000510] [PMID]

[20] Snarr RL, Esco MR. Electromyographical comparison of plank variations performed with and without instability devices. The Journal of Strength \& Conditioning Research. 2014; 28(11):3298-305. [DOI:10.1519/JSC.0000000000000521] [PMID]

[21] Miller WM. Assessment of electromyographic activity during a TRXO split-squat and traditional split squat [PhD dissertation]. Cape Girardeau, Missouri: Southeast Missouri State University; 2015.

[22] Gillespie G. An analysis of the muscle activation of a push Up when instability is introduced [PhD dissertation]. Indiana, Pennsylvania: Indiana University of Pennsylvania; 2012.

[23] Prentic WE. Rehabilitation techniques for sports medicine and athletic training. Boston: McGraw Hill; 2003.

[24] Bressel E, Yonker JC, Kras J, Heath EM. Comparison of static and dynamic balance in female collegiate soccer, basketball, and gymnastics athletes. Journal of Athletic Training. 2007; 42(1):42-6. [PMID]

[25] Huang PY, Lin CF. Effects of balance training combined with plyometric exercise in postural control: Application in individuals with functional ankle instability. Paper presented at: $6^{\text {th }}$ World Congress of Biomechanics (WCB 2010). 1-6 August 2010; Singapore, Singapore.

[26] Myer GD, Ford KR, McLean SG, Hewett TE. The effects of plyometric versus dynamic stabilization and balance training on lower extremity biomechanics. The American Journal of Sports Medicine. 2006; 34(3):445-55. [DOI:10.1177/0363546505281241] [PMID]

[27] Golara K. [Suspension training total body resistance exercise 2016: Federation of sport for all (Persian)]. Tehran: Ayandegan; 2017. 
[28] Dawes J. Complete guide to TRX suspension training. Champaign, Illinois: Human Kinetics; 2017.

[29] Hübscher M, Zech A, Pfeifer K, Hänsel F, Vogt L, Banzer W. Neuromuscular training for sports injury prevention: A systematic review. Medicine and Science in Sports and Exercise. 2010; 42(3):413-21. [DOI:10.1249/MSS.0b013e3181b88d37]

[30] Lederman E. Neuromuscular rehabilitation in manual and physical therapies: Principles to practice. Amsterdam: Elsevier Health Sciences; 2010.

[31] Holm I, Tveter AT, Fredriksen PM, Vøllestad N. A normative sample of gait and hopping on one leg parameters in children 7国 12 years of age. Gait \& Posture. 2009; 29(2):317-21. [DOI:10.1016/j.gaitpost.2008.09.016] [PMID]

[32] Kim JH, Kim YE, Bae SH, Kim KY. The effect of the neurac sling exercise on postural balance adjustment and muscular response patterns in chronic low back pain patients. Journal of Physical Therapy Science. 2013; 25(8):1015-9. [DOI:10.1589/jpts.25.1015] [PMID] [PMCID]

[33] Babakhani F, Oladghobadi K, Fatahi F. [Effect of hip abductor muscle fatigue on static and dynamic balance in elderly women (Persian)]. Iranian Journal of Ageing. 2016; 11(2):322-9.

[34] Kim GY, Kim SH. Effects of push-ups plus sling exercise on muscle activation and cross-sectional area of the multifidus muscle in patients with low back pain. Journal of Physical Therapy Science. 2013; 25(12):1575-8. [DOI:10.1589/ jpts.25.1575] [PMID] [PMCID] 
Appendix 1. Four-week exercises designed by the researcher with TRX

\begin{tabular}{|c|c|c|}
\hline Week & Exercise & Set $\times$ Repeat \\
\hline \multirow{5}{*}{1} & Jump squat & $3 \times 10$ \\
\hline & Assisted lunge & $3 \times 10$ \\
\hline & & \\
\hline & Split lunge & $2 \times 10$ \\
\hline & High knees lunge & $2 \times 10$ \\
\hline \multirow{5}{*}{2} & Jump squat & $3 \times 10$ \\
\hline & Assisted lunge & $3 \times 10$ \\
\hline & Split lunge & $3 \times 10$ \\
\hline & High knees lunge & $3 \times 10$ \\
\hline & Side step lunge & $2 \times 10$ \\
\hline \multirow{7}{*}{3} & Single leg squat and hop & $3 \times 10$ \\
\hline & Suspended abducted lunge and hop & $3 \times 10$ \\
\hline & Suspension lunge and hop & $3 \times 10$ \\
\hline & & \\
\hline & (Figure 8 hop) & $3 \times 10$ \\
\hline & Single leg burpee+hip abduction & $3 \times 10$ \\
\hline & High knee drive & $3 \times 10$ \\
\hline \multirow{7}{*}{4} & Single leg squat and hop & $3 \times 10$ \\
\hline & Suspended abducted lunge and hop & $3 \times 10$ \\
\hline & Suspension lunge and hop & $3 \times 10$ \\
\hline & & \\
\hline & (Figure 8 hop) & $3 \times 10$ \\
\hline & Single leg burpee+hip abduction & $3 \times 10$ \\
\hline & High knee drive & $3 \times 10$ \\
\hline
\end{tabular}

PHYSICAL TREATMENTS
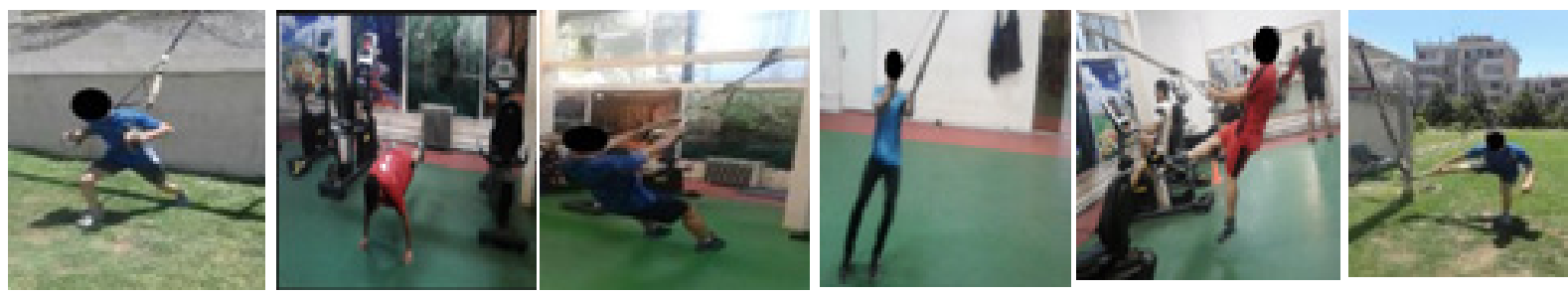

Appendix 2. A sample of TRX exercise 
Appendix 3. Hopping exercise

\begin{tabular}{|c|c|c|c|}
\hline Week & $\begin{array}{l}\text { Exercise Volume (Number of Contacts With } \\
\text { the Ground in Each Exercise Session) }\end{array}$ & Exercise & Setxrepeat \\
\hline \multirow{5}{*}{1} & \multirow{5}{*}{100} & Single leg side-to-side hop (hands free) & $3 \times 10$ \\
\hline & & Single leg forward and backward hop (hands free) & $3 \times 10$ \\
\hline & & & \\
\hline & & Single leg hopping forward (hands free) & $2 \times 10$ \\
\hline & & Single leg zigzag hopping (hands free) & $2 \times 10$ \\
\hline \multirow{5}{*}{2} & \multirow{5}{*}{140} & Single leg side hop (arms crossed on chest) & $3 \times 10$ \\
\hline & & Single leg forward and backward hopping (arms crossed on chest) & $3 \times 10$ \\
\hline & & Single leg forward hopping (hands free) & $3 \times 10$ \\
\hline & & Single leg zigzag hopping (hands free) & $3 \times 10$ \\
\hline & & Single leg square hop (hands free) & $2 \times 10$ \\
\hline \multirow{7}{*}{3} & \multirow{7}{*}{180} & Single leg side-to-side hop (arms crossed on chest) & $3 \times 10$ \\
\hline & & Single leg forward and backward hopping (arms crossed on chest) & $3 \times 10$ \\
\hline & & Single leg hopping forward (arms crossed on chest) & $3 \times 10$ \\
\hline & & & \\
\hline & & Single leg zigzag hopping (arms crossed on chest) & $3 \times 10$ \\
\hline & & Single leg square hop (hands free) & $3 \times 10$ \\
\hline & & Both legs figure 8 hop (hands free) & $3 \times 10$ \\
\hline \multirow{7}{*}{4} & \multirow{7}{*}{180} & Single leg side-to-side hop (arms crossed on chest) & $3 \times 10$ \\
\hline & & Single leg forward and backward hop (arms crossed on chest) & $3 \times 10$ \\
\hline & & Single leg hopping forward (arms crossed on chest) & $3 \times 10$ \\
\hline & & & \\
\hline & & Single leg zigzag hopping (arms crossed on chest) & $3 \times 10$ \\
\hline & & Single leg square hop (arms crossed on chest) & $3 \times 10$ \\
\hline & & Single leg figure 8 hop (hands free) & $3 \times 10$ \\
\hline
\end{tabular}

PHYSICAL TREA MENTS
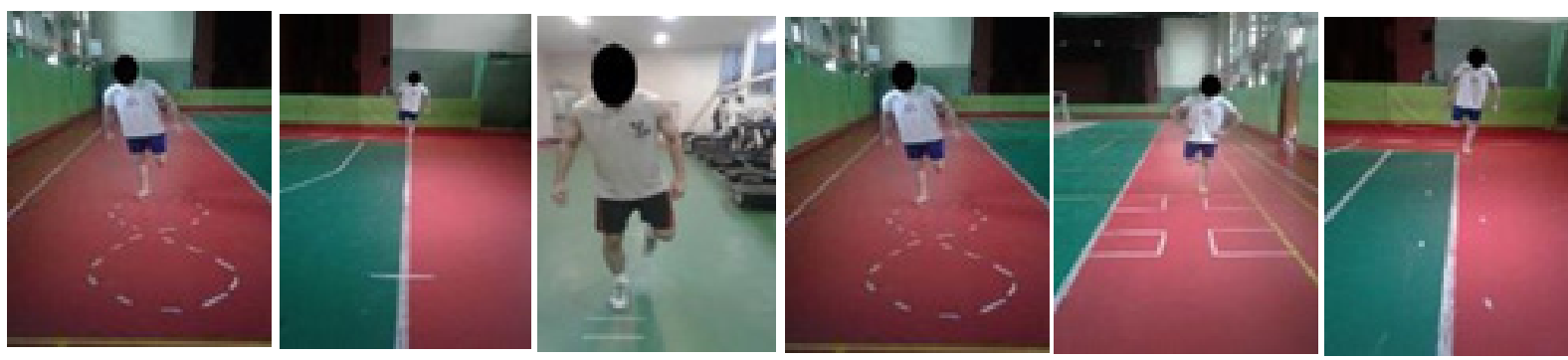

Appendix 4. Example of hopping exercises

PHYSICAL TREATMENTS 